\title{
Einfluss der kolloidalen Lösung auf die Rückresorption des Kreatinins in der Niere.
}

(Studien über Flüssigkeitsaustausch. XXXXII.)

Von

Koichi Aida.

(會田宏一)

(Aus der Medizinischen Klinik von Prof. Dr. T. Kato,

Tohoku Reichsuniversität zu Sendai.)

Es haben neuerdings Shoji u. Takedal) bei Durchspülung der isolierten Krötenniere mit Normal-Ringerlösung aus Nierenarterie, indem sie bei Durchströmung mit Kreatinin-Ringer von den Ureteren aus intratubulär unter einem Druck von $14 \mathrm{~cm} \mathrm{H}_{2} \mathrm{O}$ rückläufig einfliessen liessen, die Permeabilität der Nierenepithelien für Kreatinin bei der gesunden sowie geschädigten Niere untersucht und den Nachweis erbracht, dass, während normale Nierenepithelien kaum oder gar nicht durchlassen, bei geschädigtn Nierenepithelien der Durchgang des Kreatinins sehr leicht vonstatten geht. Sie haben hierdurch die Tatsache erfasst, dass bei geschädigten Nierenepithelien sich eine pathologische Steigerung ihrer Permeabilität abspielt. Es wurden in der Folge einschlägige Versuche in dieser Beziehung von Yamaguchi u. Mitarbeitern ${ }^{2}$ mit Kongorot und von $\mathrm{Adachi}$ u. Kasugai ${ }^{3)}$ mit Harnstoff ausgeführt. Sie haben in Anlehnung an die Ansicht Yamaguch is ${ }^{4}$, die Meinung dahin ausgesprochen, dass bei geschädigten Nierenepithelien die hemmende Wirkung auf die Rückresorption abgeschwächt wird.

Nach der Meinung Cushny $y^{5)}$ u. Richards ${ }^{6}$ ist das Kreatinin Nichtschwellenkörper, nach Rehberg7) wird ebenfalls das Kreatinin zwar aus den

1) Shojiu. Takeda, Tohoku Journ. Exp. Med., 1935, 26, 592.

2) Yamaguchi, Takahashi, Takeda u. Shoji, Ibid., 1933, 20, 331.

3) Adachiu. Kasugai, Ibid., 1933, 20, 350.

4) Yamaguchi, Ibid., 1930, 16, 367.

5) Cushny, The Secretion of the Urine. 2. Aufl, London 1926, S. 28 u. 52.

6) Richards, Zit. n. Volhard: Mohr u. Staehelin's Handb. d. inner. Med., 2. Aufl, Berlin 1931. VI/2, S. 1165.

7) Rehberg u. Holton, Act. med. Scand., 1931, 74, 479. 
Glomeruli ausgeschieden aber in den Tubulusepithelien nicht rückresorliert. Es ist allgemein bekannt, dass das Kreatinin bei irgendeiner Funktionsstörung der Niere im Blut zurückgehalten wird, wie sonstige Harnbestandteile.

Wie in meinen vorhergien Mitteilungen ${ }^{89}$ 9) berichtet, babe ich die Durchspülung der Krötenniere mit kolloidalen Lösungen, wie Gummi-Ringer oder Rinderserum-Ringer, ausgeführt, um zu untersuchen, welche Einflüss derartige kolloidale Lösungen auf die intrarenale Harnabsonderung und auf den Kochsalzghealt im Harn ausübt, und konnte die Tatsache erheben, dass die Existenz des Kolloides in der Spülflüssigkeit eine Herabsetzung der Nierenepithelfunktion verursacht, die zur abnormen Steigerung der Rückresorption führt. Und dies Phänomen führte ich auf die Herabsetzung der die Rückresorption regulierenden bzw. beschränkenden Kraft der Tubulusepithelien zurück. In vorliegendem Versuch wurde die Rinderserum-Ringerlösung als Spülfüssigkeit gewährt, und mit eben demselben Verfahren wie in vorausgegangenen Mitteilungen die Frage in Angriff genommen, was für einen Einfluss das Kolloid auf die Permeabilität der Nierenepithelien für Kreatinin ausüben wird.

Versuchsmethode: In vorliegendem Versuch war das Verfahren dasselbe wie in den letzten Mitteilungen ${ }^{899}$. Zwecks Erzeugung der Nierenschädigung wurden Uranylnitrat sowie Kantharidin angewandt. Was Spülflüssigkeit anbetrifft, so wurde sie in der Weise bereitet, dass Kreatinin (Merck) in einer Konzentration von $0,1 \%$ in Ringerlösung gelöst, die so hergestellte Spülfüssigkeit wurde von der $\mathrm{A}$. renalis aus und die Rinderserum-Ringer* von der $\mathrm{V}$. renoportalis aus gesondert hineinfliessen lassen. Vor dem Versuch wurde zuerst die Durchspülung mit der Normal-Ringer von A. renalis sowie V. renoportalis aus vorgenommen, um das Blut in der Niere zu vertreiben; und nachdem jede Zufuhrmenge ziemlich konstant geworden ist, wurde $0,1 \%$ ige Kreatinin-Ringer 10 Minuten lang zu A. renalis hineinfliessen lassen. Darauf wurde die Durchspülung von V. renoportalis $30 \mathrm{Min}$. lang mit Normal-Ringer durchgeführt, dann auf die Rinderserum-Ringer umgeschaltet, und 50 Min. lang fortgesetzt. Der Uretertropfen wurde alle $10 \mathrm{Min}$. vom Beginn des Versuchs in einem kleinen Kölbchen gesammelt. Die quantitative Bestimmung des Kreatinins wurde nach der Folinschen ${ }^{10)}$ Methode durch geführt ; gleichzeitig wurden die Zufuhrmenge der Durchspülungsflüssigkeit zu A. renalis und zu V. renoportalis sowie die Ausfuhrmenge aus V. cava post. alle 10 Minuten bestimmt. Der Druck der von A. renalis aus hineinfliessenden Flüssigkeit

8) A id a, Tohoku Journ. Exp. Med., 1943, 45, 250.

9) A id a, Ibid., 1943, 45, 266.

* Über die Herstellung der Rinderserum-Ringer ist in meiner anderen Mitteilung"9 ausführlich beschrieben.

10) Folin, Journ. Biol. Chem., 1914, 17, 469. 
wurde auf $24 \mathrm{~cm} \mathrm{H}_{2} \mathrm{O}$, der Druck der von $\mathrm{V}$. renoportalis aus hineinfliessenden auf $12 \mathrm{~cm} \mathrm{H}_{2} \mathrm{O}$ festgesetzt.

\section{Vorbereitender Versuch. Durchspülung mit Normal-Ringer.}

1. Versuch an der gesunden Niere.

In vorliegender Versuchsteihe wurden 5 Versuche angestellt. Als Versuchsbeispiel ist Versuch 1. illustriert (Fig. 1.).

In allen Fällen nahm die Harnmenge mit dem Zeitverlauf ab, die Kreatininkonzentration stieg auf, um nach ca. 30 Min. konstant zu bleiben(116 $\mathrm{mg} / \mathrm{dl}-120 \mathrm{mg} / \mathrm{dl}$ ). Es gab aber Fälle, die im letzten Stadium der Versuche eine äusserst geringe Abnahme des Kreatiningehalts aufwiesen. Die $\mathrm{Zu}-$ fuhrmenge zur A. renalis nahm mit Zeitablauf mehr oder minder ab; es war aber keine nennenswertige Gefässwirkung nachweisbar.

\section{Versuch an der Kanthari- dinniere.}

In vorliegender Versuchsreihe wurden 5 Versuche angestellt. Im ganzen genommen, liegen die Verhältnisse zwar ähnlich, wie bei der gesunden Niere, aber die Kreatininkonzentration steigerte sich allmählich mit dem Zeitablauf, und konnte kaum die Neigung zur Stetigkeit zeigen; sie erreichte 40 Min. nach Beginn des Versuchs den höchsten Wert $(111 \mathrm{mg} / \mathrm{dl}-115 \mathrm{mg} / \mathrm{dl})$. Die Neigung zur Abnahme, die sich am Ende des Versuchs zum Vorschein kommt, war etwas deutlicher im Vergleich mit derjenigen bei der gesunden
Fig. 1.

Vorbereitender Versuch (gesunde Niere). Versuch 1. Von Nierenarterie aus mit 0,1\%iger Kreatinin-Ringerlösung und von Nierenpfortader aus mit NormalRinger durchspült.

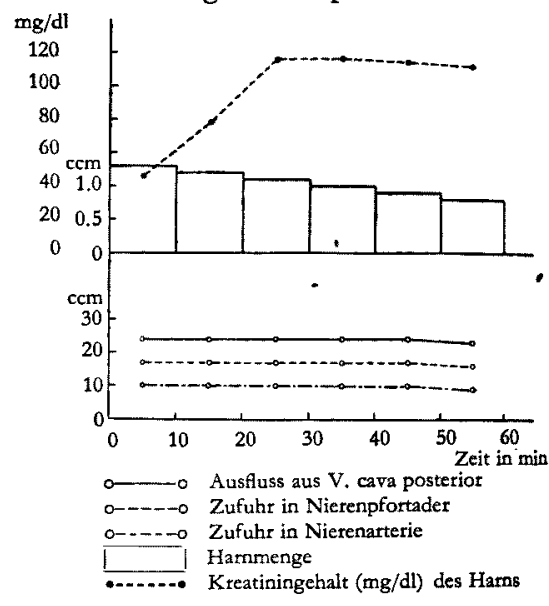

Fig. 2.

Vorbereitender Versuch (Kantharidinniere).

Versuch 5. Von Nierenarterie aus mit $0,1 \%$ iger Kreatinin-Rigerlösung und von Nierenpfortader aus mit Normal-Ringer durchspült.

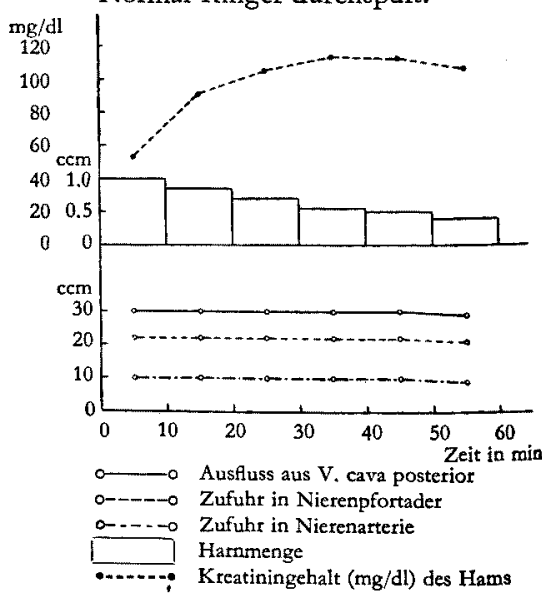


Niere. Die Harnmenge war spärlicher als bei der gesunden Niere und setzte sich mit dem Zeitablauf stärker herab. Die Zufuhrmenge verhielt sich in nahezu ähnlicher Weise wie bei der gesunden Niere. (Fig. 2).

Fig. 3. Vorbereitender Versuch (Uranniere).

Versuch 5. Von Nierenarterie aus mit $0,1 \%$ iger Kreatinin-Ringerlösung und von Nierenpfortader aus mit

Normal-Ringer durchspült.

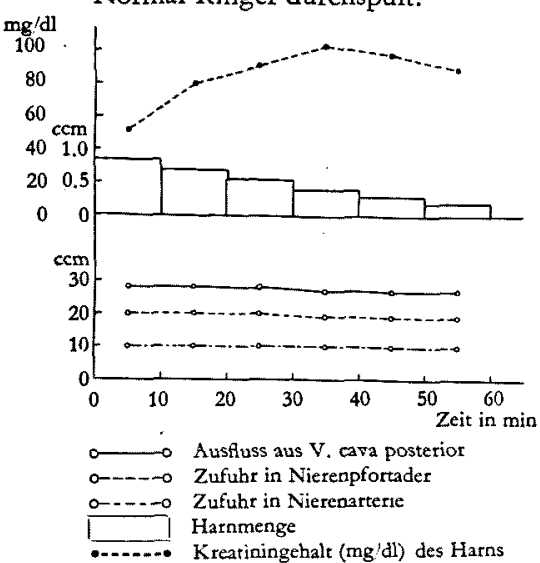

3. Versuch an der Uranniere.

In vorliegender Versuchsreihe war bei allen 5 Versuchen die Harnmenge weniger als bei der gesunden Niere sowie der Kantharidinniere und verminderte sich mit dem Zeitablauf stärker. Die Kreatininkonzentration steigerte sich vom ersten Stadium an, erreichte ca 30-40 Min. nach dem Beginn des Versuchs das Maxinum ( $99 \mathrm{mg} / \mathrm{dl}-104$ $\mathrm{mg} / \mathrm{dl}$ ), um dann grössere Abnahme als bei der gesunden Niere sowie der Kantharidinniere zu zeigen. Hierbei war auch die Gefässwirkung nicht nachweisbar. (Fig. 3).

II. Einfluss der renoportalen Durchspülung mit RinderserumRingerlösung auf die Rückresorption des Kreatinins.

Fig. 4. Gesunde Niere. Versuch 1. Von Nierenarterie aus mit 0,1\%iger Kreatinin-Ringerlösung und von Nierenpfortader aus mit RinderserumRingerlösung durchspült.

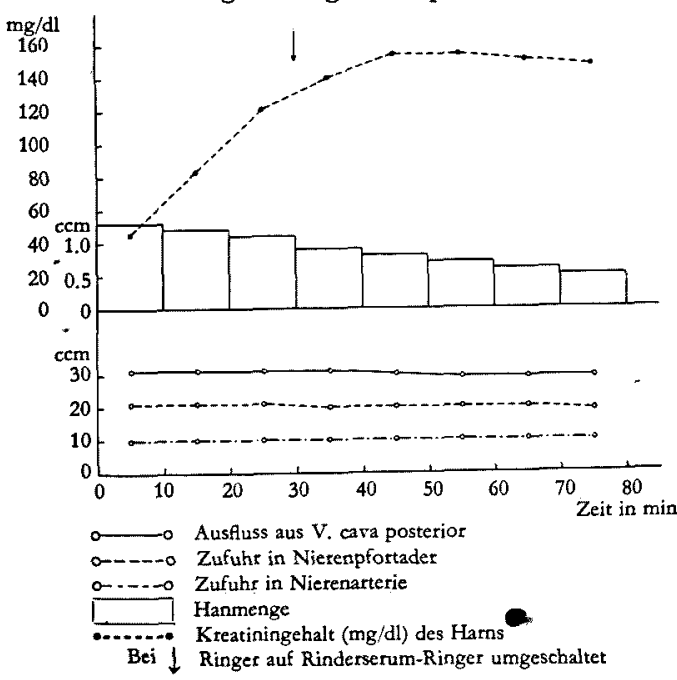

Zwecks derVereinfachung der Erörterung wird im folgenden der Zeitraum der Durchspülung mit Normal-Ringer allein als I. Stadium, derjerige der Durchspülung mit Rinderserum-Ringerlösung als II. Stadium bezeichnet.

1. Versuch an der gesunden Niere.

Es wurden 5 Versuche ausgeführt. Die Befunde im I. Stadium waren nicht verschieden von derselben im vorbereitenden Versuch, aber im II. Stadium trat eine erhebliche Abnahme der Harnmenge auf, 
wobei die Kreatininkonzentration auffallend anstieg. Während diese mit dem Zeitablauf beinah konștant blieb, zeigte sie später eine kleine Abnahme. Im I. Stadium stand der Kreatiningehalt dem bei im folgenden darzustellenden pathologischen Nieren nach, aber im II. Stadium zeigte es eine unerwartete Erhöhung ( $151 \mathrm{mg} / \mathrm{dl}-161 \mathrm{mg} / \mathrm{dl}$ ), die diejenige bei der Kantharidinniere sowie der Uranniere bei weitem übertraf. Die Zufuhrmenge von der Nierenarterie aus zeigte mit der Zeit die Tendenz zu mehr oder minder Abnahme, aber keine nennswerte Gefässwirkung war erkennbar. An der Nierenpfortader war im II. Stadium eine ganz geringfügige Gefässwirkung nachweisbar. (Fig. 4).

2. Versuch an der Kantharidinniere.

5 Versuche wurden ausgeführt. Im I. Stadium war nichts verschieden vom vorbereitenden Versuch, im II. Stadium aber war die Abnahme des Harns auffälliger als bei der gesunden Niere. Die Kreatininkonzentration zeigte eine rasche Erhöhung, aber erreichte in 20 Min. nach der Umschaltung auf Serum-Ringer den höchten Wert (141 mg/dl-148 mg/dl), wies von da an keine Tendenz zur Stetigkeit auf wie bei der gesunden Niere, neigte sich dagegen immer mehr zur Abnahme. Der Kreatinigehalt im I. Stadium war beträchtlịch und übertraf denjenigen bei der gesunden Niere sowie der Uranniere, zeigte zwar im II. Stadium eine rasche Erhöhung, die aber nicht so stark wie bei

Fig. 5. Kantharidinniere. Versuch 2. Von Nierenarterie aus mit $0,1 \%$ iger Kreatinin-Ringerlösung und von Nierenpfortader aus mit RinderserumRingerlötung durchspült.

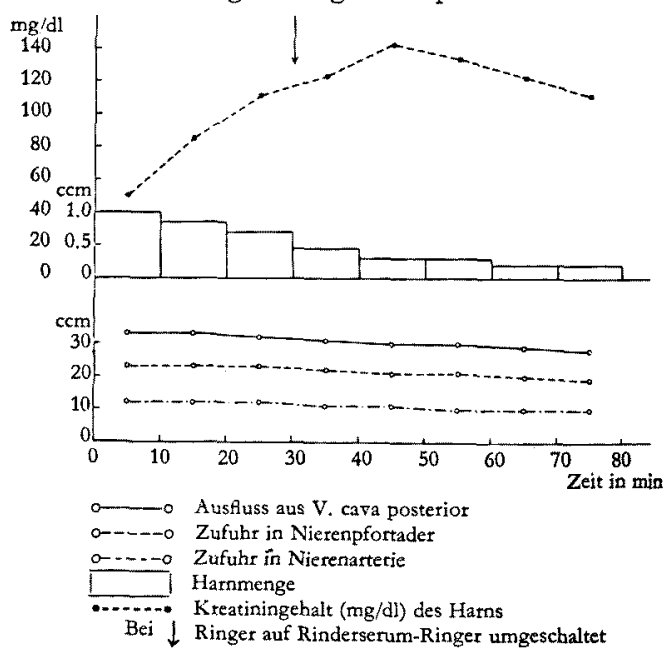
der gesunden Niere war, und um die Mitte zwischen derjenigen bei der Uranniere und derjenigen bei der gesunden Nierestand. Die Zufuhrmenge war beinahe gleich wie bei der gesunden Niere. (Fig. 5).

3. Versuch an der Uranniere.

Es wurden 8 Versuche ausgeführt. Im grossen und ganzen wurde hier ein ähnliches Bild angetroffen, wie es bei der Kantharidinniere geschildert worden ist. Die Harnmenge erwies sich aber von Anfang an weniger und zeigte mit dem Zeitablauf grössere Verminderung. Die Kreatininkonzentration stand im I. Stadium in der Mitte zwischen derjenigen bei der gesunden Niere 
und derjenigen bei der Kanthatidinniere, im II. Stadium erhöhte sich und kam $20 \mathrm{Min}$. nach der Umschaltung auf die Serum-Ringer-Lösung am Maximum (120 mg/dl-132 mg/dl), an, das aber nicht so gross wie bei der gesunden Niere und der Kantharidinniere war. Gegen Versuchsende trat ihre erhebliche Herabsetzung auf. (Fig. 6).

Kurz zusammengefasst, im vorbereitenden Versuch, in welchem die Durchspülung mit Normal-Ringer ausgeführt wird, tritt Oligurie nebst der
Fig. 6. Uranniere. Versuch 1. Von Nierenarterie aus mit $0,1 \%$ iger Kreatinin-Ringerlösung, von Nierenpfortader aus mit RinderserumRingerlösung durchspült.

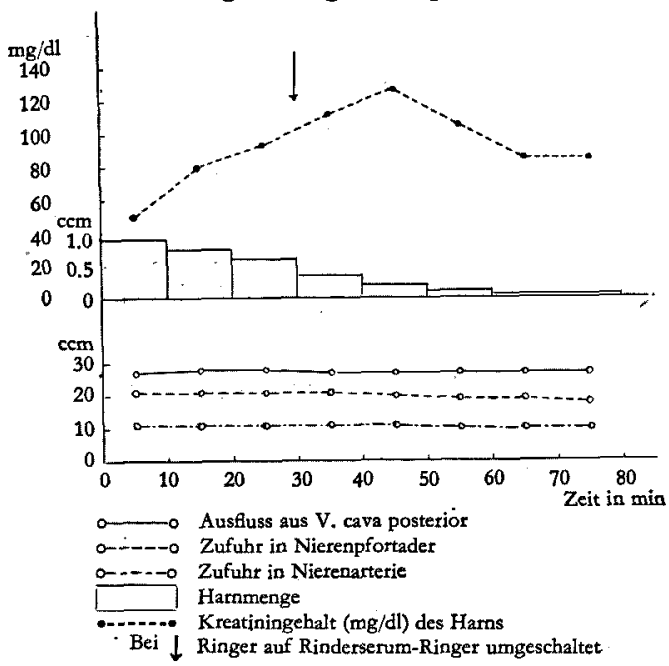

Erhöhung der Kreatininkonzentration bis zu einem gewissen Grand ein. Bei der gesunden Niere ist die Oligurie mindestgradig, die Erhöhung der Kreatininkonzentration dagegen höchstgradig. Bei der Kantharidinniere wird die Harnverminderung etwas auffälliger als bei der gesunden Niere, und die Kreatininkonzentration erreicht sehr verzögert den höchsten Wert, um dann allmählich zu vermindern. Die Oligurie kommt bei der Uranniere ausgeprägt zutage, und auch der in den sog. Harn ausgeschiedene Kreatiningehalt zeigt den kleinsten Wert, sein Vermehrungsgrad ist ebenfalls am wenigsten. Ferner ist die Neigung der Kreatininkonzentration gegen Endstadium des Versuchs abzunehmen, auffallend.

Bei renoportaler' Durchspülung mit Serum-Ringer tritt, sowohl im gesunden als auch in pathologischen Zuständen, im II. Stadium stets eine erhebliche Oligurie auf, die sich bei der Uranniere am stärksten, bei der Kantharidinniere weniger stark und bei der gesunden Niere am wenigsten einstellt. Der Kreatiningehalt des Harns ist bei-der gesunden Niere am grössten, und je nach der Intensität der Nierenepithelschädigung nimmt die Konzentration des in den Harn ausgeschiedenen Kreatinins nimmt stärker ab, nämlich die Uranniere weist den minimalen und die Kantharidinniere den mittleren Wert auf.

Wenn man alle oben angeführten Versuchsergebnisse noch eingehender auseinandersetzt, so ist beim vorbereitenden Versuch der Kreatiningehalt im sog. Harn zwar im Anfangsstadium des Versuchs bei der gesunden Niere klein, nimmt aber mit dem Zeitablauf zu, um ca. 30 Min. nachher 
konstant zu werden. Wie es schon Shoji u. Takeda ${ }^{1)}$ nachgewiesen haben, wird das Kreatinin durch Tubulusepithelien nicht rückresorbiert, und der Glomerulusharn wird durch Rückresorption des Wassers selbst mehr als vorher konzentriert, infolgedessen steigt die Kreatininkonzentration mit der Zeitablauf allmählich auf, um dann in einer bestimmten Höhe zu bleiben. Bei der Kantharidinniere, im welcher die. Einschränkung auf die Filtration abgeschwächt ist, wächst auch das Glomerulusfiltrat selbst im Vergleich mit dem Falle der gesunden Niere stärker an, folglich muss der Kreatiningehalt im Harn ebenfalls zugenommen haben. Aber hierbei sind die Nierenepithelien auch mindestens funktionell angegriffen, dadurch findet die Rückresorption in den Tubulis lebhaft statt, so dass die Konzentration des in Uretertropfen ausgeschiedenen Kreatinins schon von Anfang an eine Erhöhung zeigt, deren Grad nicht so sehr merklich wie bei der gesunden Niere ist. Auch die Tendenz der Kreatininkonzentration zur nachher erfolgenden Stabilität tritt verzögert ein. Bei solchen geschädigten Nierenepithelien setzt sich die Durchlässigkeit auch für das Kreatinin ein, wodurch die Kreatininkonzentration im Spätstadium des Versuchs Neigung zur Verminderung aufweist. Bei der Uranniere, in welcher der Funktionsausfall der Nierenepithelien sehr ausgeprägt eingestellt ist, ist ihre hemmende Wirkung auf die Rückresorption erheblich abgeschwächt und die dadurch bedingte Steigerung der Rückresorption führt zur hochgradigen Oligurie, wobei, weil das Kreatinin ebenfalls leicht rückresorbiert wird, die Kreatininkonzentration im sog. Harn am wenisten zunimmt und die $\mathrm{Ab}$ nahme des Kreatiningehaltes des Harns im Spätstadium des Versuchs sich stärker einstellt. Was den Wirkungsmechanismus bei renoportaler Durchspülung mit kolloidaler Lösung anbetritt, so ist er schon in vorherigen Mitteilungen eingehend erörtert. Kurzum, durch den stärkeren kolloid-osmotischen Druck derSpülflüssigkeit selbst wird einerseits dieFunktionsherabsetzung der Nierepithelien verursacht, also die Durchlässigkeit der Nierenepithelien gesteigert, anderseits der Glomerulusharn in der stärkèm Masse in die renoportalen Gefässe eingezogen, so dass es zu einer abnormen Steigerung der Rückresorption führt. Ein solches Phänomen, das durch kolloidale Lösungen verursacht wird, ist schon von Ellinger u. Heymann ${ }^{11)}$, Nonnenbruch ${ }^{12)}$, Drinker ${ }^{13)}, S_{\text {ato }}{ }^{14)}, K_{i t a m u r a}{ }^{15)}$ u. a. bestätigt worden.

Bei der gesunden Niere findet in den Nierenepithelien im II. Stadium durch die Wirkung der Serum-Ringerlösung eine auffallende Zunahme der

11) Ellinger u. Heymann, Arch. f. exp. Pathol. u. Pharm., 1921, 90, 336.

12) Nonnen bruch, Ibid., 1921, 91, 218.

13) Drinker, Journ. Physiol., 1927, 63, 247.

14) Sa to, Tohoku Journ. Exp. Med., 1928, 11, 489.

15) Kitamura, Folia Pharm. Japon., 1928, 4, 1. 
Rückresorption auf das Wasser statt und dadurch wird der Glomerulusharn immer mehr konzentriert, aber weil die gesunden Nierenepithelien das Kreatinin kaum durchlassen tritt, eine so rasche Zunahme der Kreatininkonzentration zu Tage. Der Grund dafür, dass sich eine geringfügige Verminderung des Kreatinin-gehaltes am Versuchsende zeigt, liegt meines Erachtens darin, dass die Zellaktivität bei überlebenden Präparaten mit dem Zeitverlauf herabgesetzt wird und allmählich in den as phyktischen Zustand gerät, wobei der Durchgang auch auf das Kreatinin selbst mehr oder weniger gestattet worden ist. Aber die genannte Herabsetzung der Kreatininkonzentration tritt unvergleichlich weniger ausgeprägt auf als bei den pathologischen Nieren. Dass die geringfügige Gefässwirkung, die sich an der V. renoportalis im II. Stadium bemerken lässt, für die Oligurie in diesem Falle gar keine Rolle spielt, darauf ist in meinen anderen Mitteilungen hingewiesen worden. Bei der gesunden Niere ist der Zunahmeporzentsatz der Kreatininkonzentration am grössten, auch die in einer Zeiteinheit ausgeschiedene absolute Kreatininmenge ist wegen der vermehrten Harnmenge grösser als bei den pathologischen Nieren. Es lässt sich also sagen, dass bei der gesunden Niere die Fähigkeit, auf die Spülflüssigkeit zu reagieren, grösser ist.

Weil bei der Kantharidinniere ausser Glomerulusschädigung auch die Tubulusepithelien wenigstens eine funktionelle Störung erleidet, verseht es sich von selbst, dass der Einfluss der Serum-Ringer stärker wird als bei der gesunden Niere, so dass der Grad der Oligurie etwas stärker wird; und weil auch die Tubulusepithelien Kreatinin selbst relativ leicht durchlassen, ist seine Konzentration im sog. Harn schwächer als bei der gesunden Niere, und wird im Spätstadium immer mehr abgeschwächt. Weil der Kreatiningehalt bei pathologischen Nieren vom Versuchsbeginn an relativ gross ist und im II. Stadium die Konzentration selbst auch derjenigen bei der gesunden Niere nachsteht, ist die Vermehrung der Kreatininkonzentration am Grade durchaus weniger als im gesunden Zustand, und auch in Bezug auf die absolute Menge steht es zwischen derjenigen bei der Norm und bei der Uranniere.

Bei der Uranniere, deren Nierenepithelien stark geschädigt sind, ist durch die Wirkung der Serum-Ringerlösung die Rückresorption beträchtlich gefördert, wodurch die Harnmenge schon vom Versuchsbeginn an spärlich ist; die Kreatininkonzentration, die im I. Stadium die der gesunden Niere übertroffen hat, steht im II. Stadium am niedrigsten und vermindert sich gegen Ende des Versuchs immer mehr.

Dies ist darauf zurückzuführen, dass das Kreatinin selbst durch die Nierenepithelien zusammen mit dem Wasser aus dem Glomerulusharn leicht rückresorbiest wird, was darauf hinweist, dass dieFunktion der geschädigten Nierenepithelien immer mehr abgeschwächt wird. $\mathrm{Da}$ übrigens bei der Uranniere 
der Prozentsatz der Zunahme des Kreatiningehalts sowie die Harnmenge am wenigsten ist im Vergleich mit dem Fall bei der intakten Niere und der Kantharidinniere, ist die in einer Zeiteinheit ausgeschiedene absolute Kreatininmenge am wenigsten.

Aus obigen Versuchsergebnissen lässt sich schliessen, dass das Kreatinin die Ninerenepithelien, solange diese intakt bleiben, gar nicht zu passieren vermag, aber bei den geschädigten Epithelien dem Grade ihrer Funktionsstörung entsprechend, sie,mit Leichtigkeit durchgehen kann. Folglich ist zu erwarten, dass, weil ein gewisser Teil von Kreatininmengen, welche durch die Glomeruli flitriert worden sind, beim Vorhandensein irgendwelcher Funktionsstörungen der Nierenepithelien in diese rückresorbiert wird und wieder in die Blutbahn tritt, der Gehalt des Blutes an Kreatinin, dem verminderten Gehalt im Harn entsprechend, zunimmt. Neubauer ${ }^{16)}$, Folin u. Denis ${ }^{17)}$, Chace u. Myers $^{18)}$, Watanabe ${ }^{19)}$, Krauss ${ }^{20)}$, Major $^{21)}$, Cope ${ }^{22)}$, Popper, Mandel u. Mayer ${ }^{23)}$, u. a. haben die Ansicht veröffentlicht, dass der Kreatiningehalts des Blutes je nach dem Grad der gestörten Nierenfunktionen zunimmt, was auch mit meinen Versuchsergebnissen in Einklang steht.

\section{Zusammenfassung.}

Es wurden gesunde sowie mit Kantharidin- oder Uranvergiftete pathologische Krötennieren im isolierten überlebenden Zustand mit RinderserumRinger durch die renoportalen Gefässe durchspült, was folgendes ergab :

1. In jedem Fall kommt eine deutliche Oligurie zustande, deren Intensität bei der Uranniere am grössten bei der gesunden am kleinsten ist.

2. Bei der gesunden Niere kann das Kreatinin die Nierenepithelien fast oder gar nicht durchpassieren, während es bei den pathologischen Nieren (Kantharidin- und Uranniere) ziemlich leicht durchgängig ist; wobei die Petmeabilität bei der Uranniere grösser als bei der Kantharidinniere ist.

3. Die Erhöhung der Kreatininkonzentration im Harn ist bei der gesunden Niere am grössten und bei der Uranniere am geringsten.

4. Die Grösse der in einer Zeiteinheit ausgeschiedenen absoluten Kreatininmenge ist ebenfalls bei der gesunden Niere maximal, während die Uran-

16) Neubau er, Münch. med. Wochenschr., 1914, 857.

17) Folin u. De nis, Journ. Biol. Chem., 1914, 17, 487.

18) Chace u. Myers, Journ. Am. Med. Assoc., 1916, 67, 929.

19) Wat na be, Kyoto Igaku Zasshi, 1918, 15, 72.

20) Krauss, Dentsch. Arch. f. klin. Med., 1922, 138, 340.

21) Major, Journ. Am. Med. Assoc., 1923, 80, 384.

22) Cope, Quart. Journ. Med., 1931, 24, 567.

23) Popper, Mandel u. Mayer, Ergeb. inn. Med., 1937, 56, 685. 
niere minimale Grösse aufweist:

Aus allen oben angeführten Ergebnissen geht nun hervor, dass beim Vorhandensein der Schädigung in den Nierenepithelien, mithin bei Funktionsstörungen derselben, der Vorgang der Rückresorption verstärkt wird, was eben mit der Ansicht Ya mag u chis in völligem Einklang steht.

Zùm Schluss drängt es mich, dem seligen Herrn Dr. Yamaguchi, Dozenten an hiesiger Klinik, für seine fortwährenden freundlichen Ratschläge bei vorliegender Atbeit meinen verbindlichsten Dank auszusprechen. 